\title{
Volume Based Measurement of Fabric Drape using Surfer Software and Studies on Effect of Influencing Factors
}

Gnanavel $\mathbf{P}^{1 *}$ and Ananthakrishnan $\mathrm{T}^{2}$

${ }^{1}$ Deptartment of Textile Technology, KSR College of Technology, Tamilnadu, India

${ }^{2}$ Dept. of Textile Technology, Govt. SKSJT Institute, Karnataka, India

\begin{abstract}
The human being needs more comfort on clothing than its color, design and appearance. Drape is one of the important factor influencing the aesthetics and comfort of fabrics. In the initial days fabric drape was measured by using Cusick's drape meter. Due to technology development and up gradation several instruments were developed by many researchers. In this research work one such latest technology was used to measure fabric drape in three dimensional way using SURFER software.
\end{abstract}

Here, the instrument used for measuring fabric drape was slightly modified from the Cusick Drape meter. The perforated circular disc was placed over the sample to measure the xyz coordinates of sample on radials range from $9.5 \mathrm{~cm}$ to $14.5 \mathrm{~cm}$ at each $5^{\circ}$ intervals. The civil engineers use $X Y Z$ coordinates to measure the surface the of land profile (either hill or valley) using software. The same concept was followed to measure the profile of drape in three dimensional way using SURFER software. The xyz values are fed as input to the software and it generates contour lines, 3D view, vector lines, drape volume and drape profile area as output.

The drape coefficient was computed from the volume of drape profile and analyzed to study the effect of six different seams, seam directions and number of stitches with two different stitch densities. The seam type, number of stitches (single/double), their interaction density * number of stitches and stitch density * seam have significant effect on volume based drape coefficient.

The calculated volume (obtained from average radius and height) is compared with volume generated by SURFER software method and it was found that there is significance difference exists.

Keywords: Drape coefficient; Seam; Seam direction; Drape meter

\section{Introduction}

Clothing is one of the fundamental needs of the human being. It acts as the interface between the body and the environment and influences the comfort perceptions of the wearer.

Clothing selection is based on the needs and desires of the people. By touching one gets information such as perception of the surface, its temperature, hardness and roughness, etc. All though in some cases it is recommended to wear certain clothing and selection is not possible, for example dress of a fire fighter, military uniform, etc. Textiles differ from other technical structures in that it must have sufficient strength and at the same time it is to be flexible, elastic and easy to pleat and shape.

The clothing satisfies some aesthetic needs or fulfills any particular demand of human being. Aesthetics is a branch of philosophy dealing with the nature of beauty, art and taste with the creation and appreciation of beauty. It is more scientifically defined as the study of sensory or sensory-emotional values. The fabrics or garments are comfortable in aesthetic and physiological sense when we evaluate textiles in traditional use [1-5].

There are number of properties of fabric which plays a significant role in aesthetic comfort. Some are listed below;

1. Bending rigidity

2. Drape

3. Thickness

4. Grams per meter square (density)

5. Surface smoothens

6. Compressibility

\section{Stretch ability}

8. Shear rigidity

9. Bulkiness

10. Surface friction

11. Air permeability

12. Moisture permeability

Drape is one of the important terms to express the comfort and aesthetics of apparel products. Drape is a property which characterizes the shape of a fabric when it is hanging down of its own weight. "Drape Co-efficient (DC)" is the main parameter used to quantify fabric drape. Several physical properties have been suggested as contributors to the drape of woven fabrics. Drapability of a fabric is combined effect of several factors such as: stiffness, flexural rigidity, weight, thickness etc. It plays a significant role in providing graceful aesthetic effects in garment [6-9].

There are number of testing instruments which are used to assess

*Corresponding author: Gnanavel P, Deptartment of Textile Technology, KSR College of Technology, Tiruchengode 637-215, Tamilnadu, India, Tel: +91-99761-67-66; E-mail: geepee_info@yahoo.co.in

Received May 13, 2014; Accepted May 16, 2014; Published May 19, 2014

Citation: Gnanavel P, Ananthakrishnan T (2014) Volume Based Measurement of Fabric Drape using Surfer Software and Studies on Effect of Influencing Factors. J Textile Sci Eng 4: 159. doi:10.4172/2165-8064.1000159

Copyright: @ 2014 Gnanavel P, et al. This is an open-access article distributed under the terms of the Creative Commons Attribution License, which permits unrestricted use, distribution, and reproduction in any medium, provided the original author and source are credited. 
Citation: Gnanavel P, Ananthakrishnan T (2014) Volume Based Measurement of Fabric Drape using Surfer Software and Studies on Effect of Influencing Factors. J Textile Sci Eng 4: 159. doi:10.4172/2165-8064.1000159

Page 2 of 6

the aesthetic comfort of fabrics. One such instrument is Cusick's drape meter. The drape node number and drape coefficient are important factors to express the drape behavior of fabric, which was calculated from the shadow obtained in drape meter.

The presence of seam line influences the drape of the fabrics. The fabric has more stiff along the seam line than the remaining parts. However, fabric drape can be more realistically investigated by considering seams. The fabric is converted into garment by means of seam. The seam is a line where two or more fabrics are joined. The stitch is the configuration of the interlacing of sewing thread in a specific repeated unit [10].

This research focuses the new method to measure the third dimension of fabric drape with an attachment designed to Cusick's drape meter and to study the effect of various seams, seam directions, number of stitches (single/double) with two stitch densities on drape. The SURFER software package generates drape profiles and provides detailed information for analysis of drape in better way (Figure 1) [1114].

\section{Materials}

To analyze the effect of various seams in different directions with two stitch densities the following yarn and fabric particulars were used (Tables 1-3)

\section{Pre-treatment}

The following sequences of pre treatment were given to the fabric.

Scouring $\rightarrow$ bleaching $\rightarrow$ cold wash $\rightarrow$ neutralization $\rightarrow$ calendaring

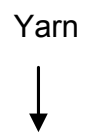

Fabric

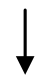

Fabric processing

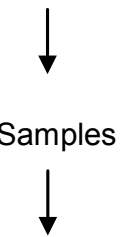

Stitch density (9 and 13)

\section{Different seams}

3 Different directions

2 Number of stitches $\left(2^{*} 6^{*} 3^{*} 2=72\right)$

Comparison and analysis

Figure 1: Experimental flow chart.

\begin{tabular}{|c|c|c|}
\hline S.No & Particulars & Values \\
\hline \multirow{2}{*}{1} & Yarn Count, Tex, (Ne $)$ & $14.7 \times 2,(2 / 40)$ \\
\cline { 2 - 3 } & CV & 2.4 \\
\hline \multirow{2}{*}{2} & Twist per cm,(TPI) & $6.85,(17.4)$ \\
\hline \multirow{2}{*}{3} & CV & 3 \\
\hline \multirow{2}{*}{4} & CSP & 5298 \\
\hline \multirow{2}{*}{4} & CV & 3.1 \\
\hline & Blend composition, $\%$ & \\
\cline { 2 - 3 } & Polyester & 65 \\
\hline
\end{tabular}

Table 1: Yarn Particulars.

\begin{tabular}{|c|c|c|}
\hline S.No & Particulars & Values \\
\hline 1 & Warp and weft yarn Count, Tex, (Ne ) & $14.7 \times 2,(2 / 40)$ \\
\hline \multirow{3}{*}{2} & Threads per $\mathrm{cm}$ & \\
\hline & Warp (Ends per Inch) & $24.4(62)$ \\
\hline & Weft (Picks per Inch) & $22.8(58)$ \\
\hline 3 & GSM & 148.3 \\
\hline \multirow{3}{*}{4} & Crimp \% & \\
\hline & Warp & 7.8 \\
\hline & Weft & 5.1 \\
\hline \multirow{3}{*}{5} & Breaking load, kg & \\
\hline & Warp way & 74.9 \\
\hline & Weft way & 63.4 \\
\hline \multirow{3}{*}{6} & Bending Length $(\mathrm{cm})$ & \\
\hline & Warp way & 2.36 \\
\hline & Weft way & 2.18 \\
\hline \multirow{3}{*}{7} & Elongation \% & \\
\hline & Warp way & 101 \\
\hline & Weft way & 13.2 \\
\hline
\end{tabular}

Table 2: Fabric Particulars

\begin{tabular}{|c|c|c|}
\hline \multirow{3}{*}{$\mathbf{1}$} & Polyester sewing thread & \\
\cline { 2 - 3 } & count, Tex, Ne & $14.5 \times 2,19.5$ \\
\cline { 2 - 3 } & Ticket Number & 99 \\
\cline { 2 - 3 } & CV & 2.2 \\
\hline \multirow{2}{*}{$\mathbf{2}$} & Twist per cm, (TPI) & $7.2,(18.3)$ \\
\cline { 2 - 3 } & CV & 5.6 \\
\hline \multirow{2}{*}{$\mathbf{3}$} & Yarn Strength, kg & 1.09 \\
\hline \multirow{2}{*}{$\mathbf{4}$} & CV & 2.32 \\
\cline { 2 - 3 } & Elongation \% & 10.9 \\
\hline
\end{tabular}

Table 3: Sewing Thread Particulars

\section{Cutting and stitching}

The fabric is cut and sewn 3 different directions (warp, weft and bias) with single \& double stitches as shown below (Figure 2).

D1 sgl: Single row of stitch parallel to warp

D1 dbl: Double row of stitches parallel to warp

D2 sgl: Single row of stitch parallel to weft

D2 dbl: Double row of stitches parallel to weft

D3 sgl: Single row of stitch in bias direction

D3 dbl: Double row of stitches in bias direction. 


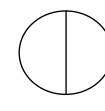

D1 sgl

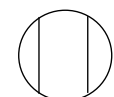

D1 dbl

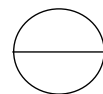

D2 sgl

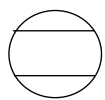

D2 dbl

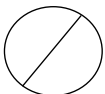

D3 sgl
D3 dbl

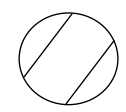

Figure 2: Seam directions.
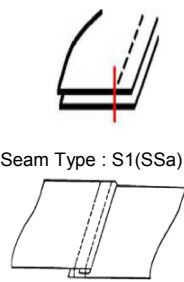

Seam Type : S4 (LSba)

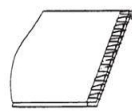

Seam Type : S2 (SSa-1)

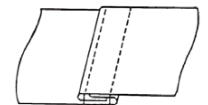

Seam Type : S5 (LSc-2)

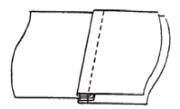

Seam Type : S3 (SSq)

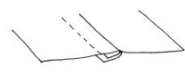

Seam Type : S6 welt seam
Figure 3: Different seam types.

\section{Stitch types}

Stitch is one unit of thread formation by passing the needle thread through the material and interlocking with a bottom thread.

SEAM. A seam is a joint consisting of a sequence of stitches uniting two or more pieces of fabric material. In this project, six most common types of seams are used to make samples from two groups, ie superimposed seam, and lapped seams.

ClassSS,SuperimposedSeams: Thesuperimposed seamsareformed by placing two plies of fabrics one over other and seam it. Superimposed seams are usually made with two plies of material, although more than two plies can be used for special projects. Types of superimposed seams used are SSa, SSa-1 and SSq.

Class LS-Lapped Seams: Lapped seams are formed by overlapping the material with sufficient distance and stitch it with one or more rows. Types of lapped seams used are LSba, LSc-2, and welt. It is shown below (Figure 3).

\section{Methodology}

\section{Surfer software method}

In this method perforated disc was placed over the sample and $\mathrm{XYZ}$ values were measured by at each 50 intervals on different radial diameters such as $19,21,23,25,27$, and 29 using specially designed scale, which is shown below (Figure 4).

The XYZ values are fed input to Surfer software, which is a gridbased mapping program that interpolates irregularly spaced XYZ data into a regularly spaced grid. The grid is used to produce different types of maps including contour, vector, image, shaded relief, 3D surface, and $3 \mathrm{D}$ wire frame maps (Figure 5).

The surfer generates grid file from $\mathrm{X}, \mathrm{Y}, \mathrm{Z}$ values which was used to generate contour map, 3D map, vector map, etc.

\section{Gridding overview}

A grid is a rectangular region comprised of evenly spaced rows and columns. The intersection of a row and column is called a grid node. Rows contain grid nodes with the same $\mathrm{Y}$ coordinate, and columns contain grid nodes with the same $\mathrm{X}$ coordinate. Gridding generates a $\mathrm{Z}$ value at each grid node by interpolating or extrapolating the data values.

\section{Advantages of using surfer}

It generates the $3 \mathrm{D}$ drape profile along with contour lines using the $\mathrm{XYZ}$ data, which is illustrated in the above figure 6).

The contour map shows lines of equal elevation (i.e. depth in this case) of the draped fabric. The lines spaced closely indicate a steeper bending, while the spaced line indicates more flatter region.

From the same map a 3D Surface can be generated which gives the visual appearance of draped sample. The Vector map shows the direction and magnitude of flow that is curvatures and also we can visualize top and front view of drape profile using this software (Figure 7).

\section{Drape profile volume measurement}

The SURFER software also measures volume of drape profile. This volume data is used as additional parameter along with drape coefficient to quantify fabric drape. The normalized volume of drape is defined as follows

Normalized Drape volume $=$ Volume of drape profile / $($ Max Volume - Min. Volume)

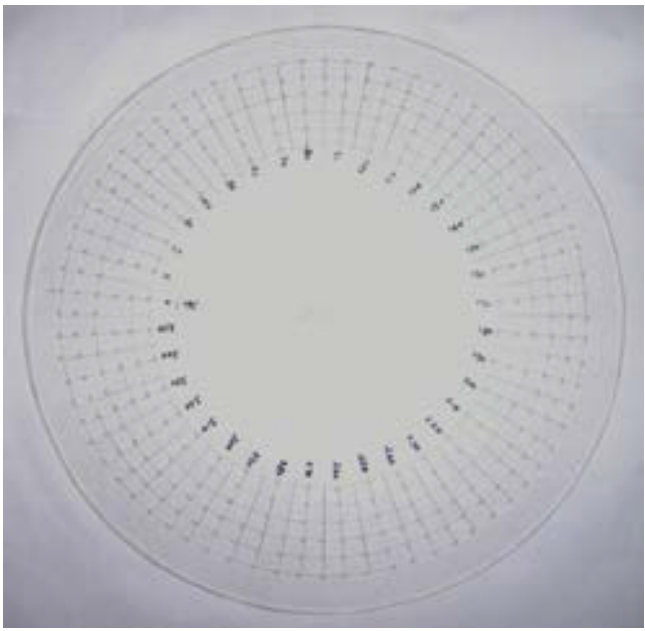

Figure 4: Circular perforated disc.

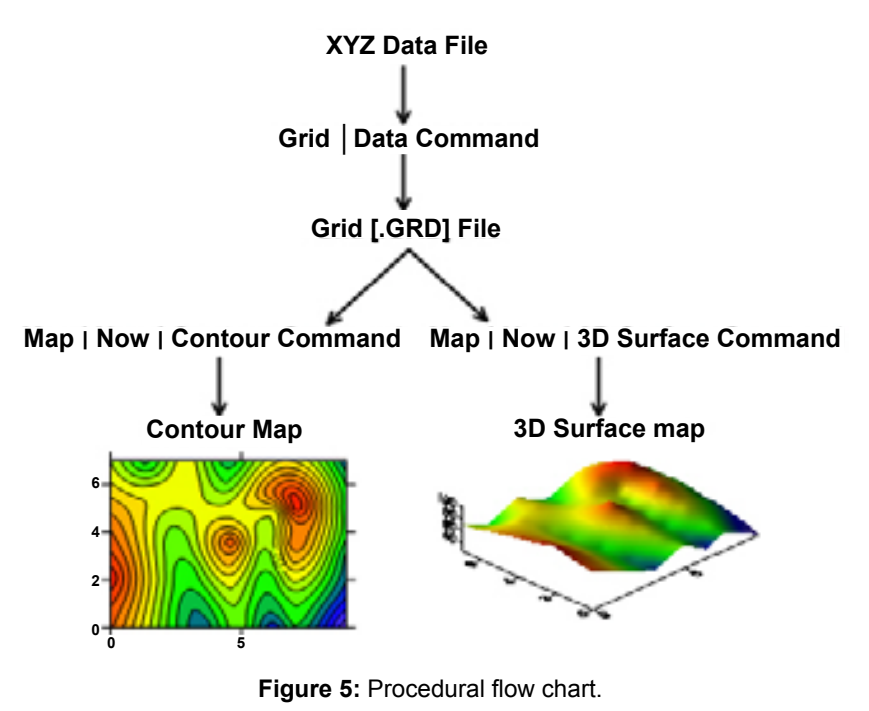



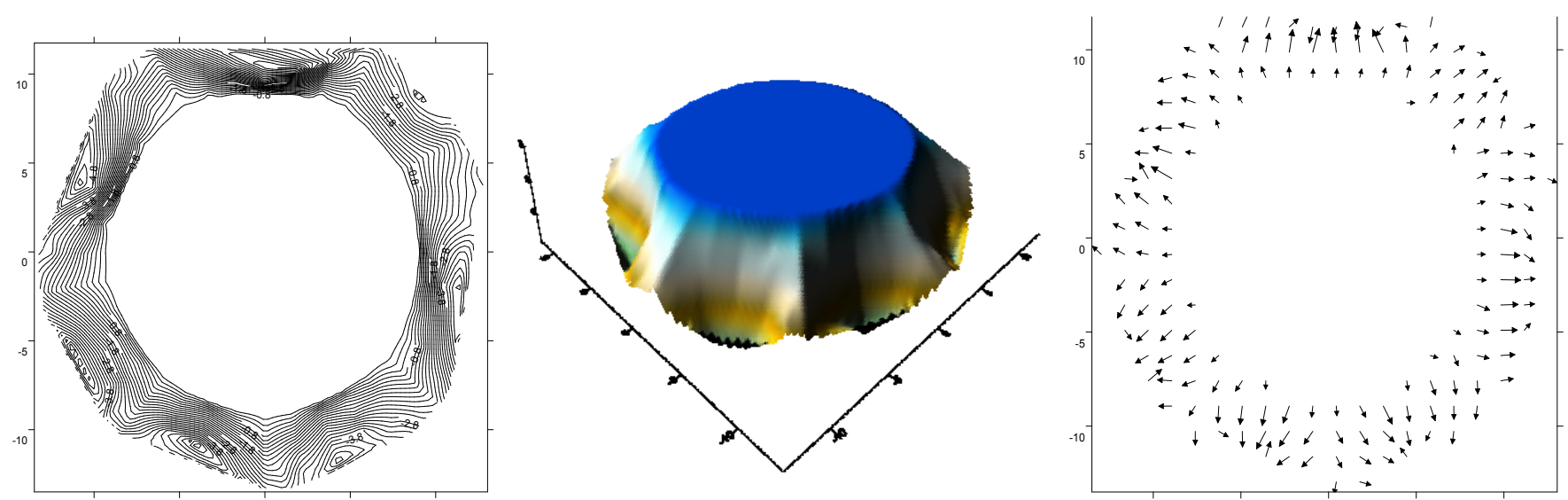

Figure 6: Contour map, 3D map and Vector map of same sample.

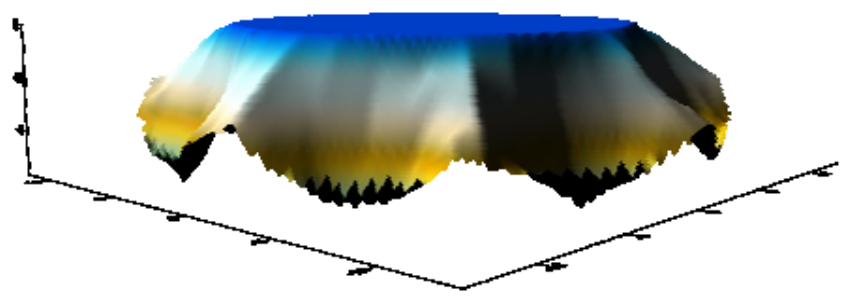

Figure 7: Rotated profile of the picture.

$=$ Volume of drape profile $/ 2715\left(3.14^{*} 15^{*} 15^{*} 6\right)-\left(3.14^{*} 9^{*} 9^{*} 6\right)$

The low value of Normalized volume indicates the material is more stiff as it increases the material bends easily $[15,16]$.

\section{Result and Discussion}

\section{Effect of stitch densities, seams, and seam direction on volume} based drape

\section{(Nominalized volume) (Table 4)}

Dependent variable: Normalized drape volume

Independent variables: Stitch density (2), Seam (6), Direction (3), Number of Stitch (2)

Null hypotheses: There is no effect of stitch density on Normalized drape volume.

There is no effect of seam on Normalized drape volume.

There is no effect of direction on Normalized drape volume.

There is no effect of number of stitches on Normalized drape volume.

There is no interaction effect of various factors on Normalized drape volume.

Alternative hypotheses: Stitch density has a significant effect on Normalized drape volume.

Density has a significant effect on Normalized drape volume.

Seam has a significant effect on Normalized drape volume.
Direction has a significant effect on Normalized drape volume.

Number of Stitches has a significant effect on Normalized drape volume.

There is a significant interaction effect of various factors on Normalized drape volume (Table 5) [17-20].

It can be seen from the above table that a high value of $\mathrm{F}_{5,37}(4.274)$ and p-value of 0.004 for the factor Seam verify that the corresponding null hypothesis is rejected at $5 \%$ level of significance.

The $\mathrm{F}_{1,37}$ value of 16.956 with a p-value of 0.000 for the factor Number of stitches (single/double) verify that the corresponding null hypothesis is significant at $5 \%$ level of significance and hence rejected.

It can also be seen from the above table that the value of $\mathrm{F}$ for the other main effect such as Density and Direction do not have any significant effect on Normalized drape volume.

The value of $F_{1,10}$ (3.264) with a p-value of 0.079 for the interaction between Density* Number of stitches verify that the null hypothesis is marginally rejected at $10 \%$ level of significance.

The $\mathrm{F}_{510}$ value of (8.517) with $\mathrm{p}$-value of 0.000 for the interaction between Density ${ }^{\star}$ Seam verify that the corresponding null hypothesis is rejected at $5 \%$ level of significance. The other interactions do not have any significant impact on Normalized drape volume.

Also it can be noted from the table that R-Square value is 0.737 , which means that the model can explain about73.7 per cent of variability in Normalized drape volume. This is higher than that of drape co-efficient (71.5 percent), thus is more discriminative measure to characterize drape. 
Citation: Gnanavel P, Ananthakrishnan T (2014) Volume Based Measurement of Fabric Drape using Surfer Software and Studies on Effect of Influencing Factors. J Textile Sci Eng 4: 159. doi:10.4172/2165-8064.1000159

Page 5 of 6

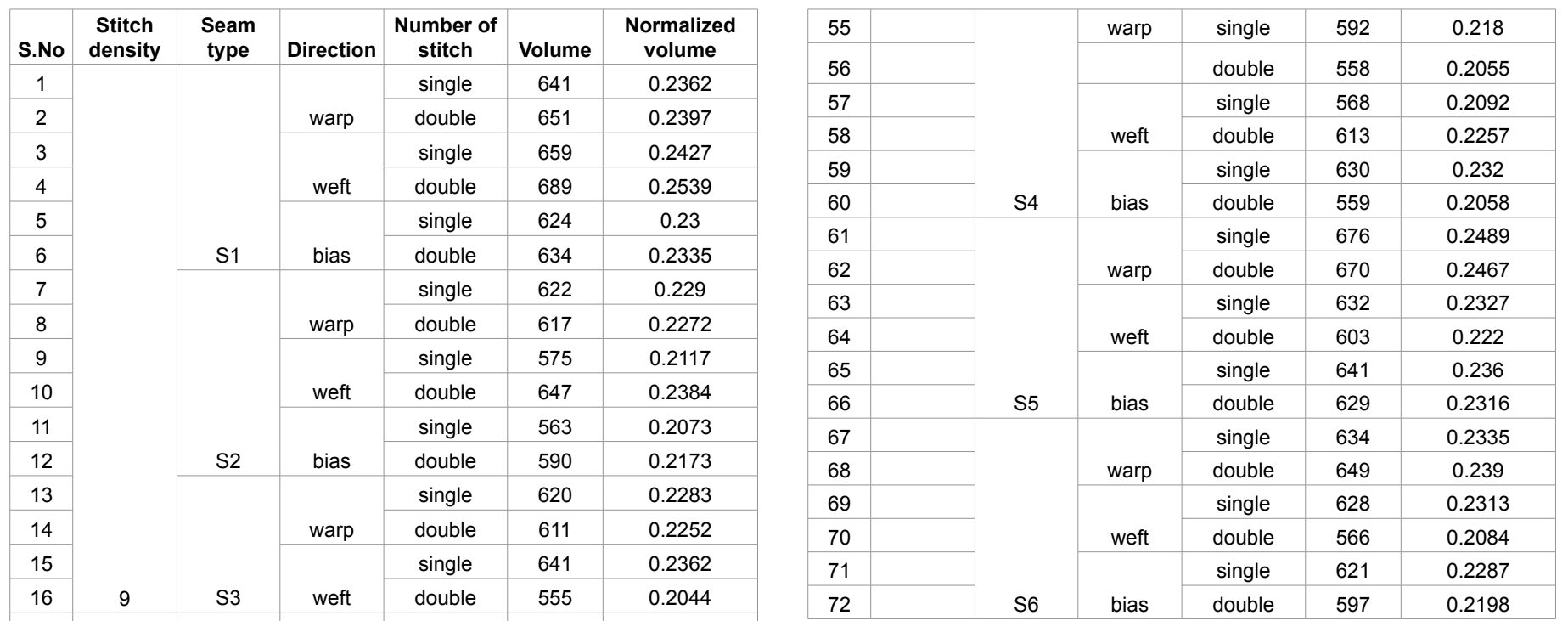

Table 4: Normalized volume values of samples in SURFER software method.

\begin{tabular}{|l|c|c|c|c|c|}
\hline Source & Sum of Squares & df & Mean Square & F & Sig. \\
\hline Density & $2.94 \mathrm{E}-05$ & 1 & $2.94 \mathrm{E}-05$ & 0.233 & 0.632 \\
\hline Seam & 0.003 & 5 & 0.001 & 4.274 & $.004^{*}$ \\
\hline Direction & 0 & 2 & 0 & 1.97 & 0.154 \\
\hline No.of.stitches & 0.002 & 1 & 0.002 & 16.96 & $.000^{*}$ \\
\hline Density * Direction & 0 & 2 & $5.17 \mathrm{E}-05$ & 0.411 & 0.666 \\
\hline Density ${ }^{*}$ No.of.stitches & 0 & 1 & 0 & 3.264 & $.079^{* *}$ \\
\hline Density ${ }^{*}$ Seam & 0.005 & 5 & 0.001 & 8.517 & $.000^{*}$ \\
\hline Direction ${ }^{*}$ No.of.stitches & 0 & 2 & 0 & 1.028 & 0.368 \\
\hline Seam ${ }^{*}$ Direction & 0.001 & 10 & $8.54 \mathrm{E}-05$ & 0.679 & 0.737 \\
\hline Seam * No.of.stitches & 0.001 & 5 & 0 & 1.177 & 0.339 \\
\hline Error & 0.005 & 37 & 0 & & \\
\hline Total & 3.523 & 72 & & & \\
\hline
\end{tabular}

$\mathrm{R}$ Squared $=.737$ (Adjusted $\mathrm{R}$ Squared $=.496)$

'Significant at $5 \%$ level of significance.

"Significant at $10 \%$ level of significance.

Table 5: Anova results of samples- Volume (Surfer method).

\begin{tabular}{|c|c|c|c|c|c|c|}
\hline S.No & $\begin{array}{l}\text { Stitch } \\
\text { Density }\end{array}$ & $\begin{array}{l}\text { Seam } \\
\text { type }\end{array}$ & Direction & $\begin{array}{c}\text { No.of } \\
\text { Stitches }\end{array}$ & $\begin{array}{l}\text { Calculated } \\
\text { volume }\end{array}$ & $\begin{array}{c}\text { Volume by } \\
\text { SURFER }\end{array}$ \\
\hline 1 & \multirow{6}{*}{13} & \multirow{6}{*}{ S1 } & \multirow{2}{*}{ Warp } & sgl & 573.7 & 673 \\
\hline 2 & & & & $\mathrm{dbl}$ & 501.5 & 569 \\
\hline 3 & & & \multirow{2}{*}{ Weft } & $\mathrm{sgl}$ & 496 & 606 \\
\hline 4 & & & & $\mathrm{dbl}$ & 522.3 & 614 \\
\hline 5 & & & \multirow{2}{*}{ Bias } & $\mathrm{sgl}$ & 524.5 & 628 \\
\hline 6 & & & & $\mathrm{dbl}$ & 509.7 & 606 \\
\hline
\end{tabular}

Table 6: computed volume and SURFER volume for seam type 1.

\section{Comparison of volume generated by SURFER software and calculated volume}

The volume of drape profile to be computed from average radius and height values and it is compared with the volume generated by SURFER software method (Table 6 and 7).

From the results there is significant difference exists between computed volume and volume by SURFER. The volume computed by average height and radius gives only the volume of frustum. It doesn't include irregularities on drape profile, but SURFER volume gives 
Citation: Gnanavel P, Ananthakrishnan T (2014) Volume Based Measurement of Fabric Drape using Surfer Software and Studies on Effect of Influencing Factors. J Textile Sci Eng 4: 159. doi:10.4172/2165-8064.1000159

Page 6 of 6

\begin{tabular}{|l|c|c|c|c|c|c|}
\hline Source of Variation & SS & df & MS & F & P-value & F crit \\
\hline Between Groups & 26878.7 & 1 & 26879 & 28 & 0.0004 & 4.9 \\
\hline Within Groups & 9730.1 & 10 & 973 & & & \\
\hline Total & 36608.9 & 11 & & & & \\
\hline
\end{tabular}

Table 7: Anova results of sample (computed volume and SURFER volume).

the exact volume of drape profile including drape nodes and other irregularities over surface [21-24].

\section{Conclusion}

Measurement of depth and analysis by SURFER software has opened up a new drape parameter namely Normalized volume based drape to be defined. The seam type, number of stitches (single/double), their interaction density ${ }^{*}$ number of stitches and stitch density ${ }^{*}$ seam have significant effect on volume based drape coefficient. The other main factors and interactions do not have significant effect on volume based drape.

The image processing method and other old techniques gives information about the 2D image of drape profile and drape profile area. Measuring the depth and use of SURFER software provides the detailed information about drape profile area, drape profile volume, 3D image of drape profile in $360^{\circ}$ with rotation, vector image, contour image and variogram. Further one can easily identify the seam line on the image. It is a new tool to quantify the drape in better way.

\section{References}

1. Mohammad G, Saghafi R, Zarrebini M, Semnani D (2011) Evaluation of Bending Modulus of Needle-Punched Fabrics Using Two Simply Supported Beam Method. Fibres Text East Eur 19: 89-93.

2. Hasani H (2010) Novel Method to Evaluate the Low-Stress Shearing Behavior of Knitted Fabrics. Fibres Text East Eur 18: 70-72.

3. Tokmak O, Berkalp OB, Gersak J (2010) Investigation of the Mechanics and Performance of Woven Fabrics Using Objective Evaluation Techniques. Part I: The Relationship between FAST, KES-F and Cusick's Drape-Meter Parameters. Fibres Text East Eur 18: 55-59.

4. Fatahi I, Yazdi AA (2010) Assessment of the Relationship between Air Permeability of Woven Fabrics and Its Mechanical Properties. Fibres Text East Eur 18: 68-71.

5. Krishnaraj K, Thanikaiselvan P, Phebeaardn K, Chandrasekaran B (2010) Effect of sewing on the drape of goat suede apparel leathers. Int J Clothing Sci Technol 22: 358-373.

6. Tien-Wei S, Pin-Ning W, Jer-Yan L (2009) Subjective and Objective Evaluation
Methods to determine the Peak-trough Threshold of the Drape Fabric Node. Textile Res J 79: 1223-1233.

7. Kun-Hsieh T, Ming-Chin T, Pin-Ning W, Tien-Wei S (2009) New Approach to Directly Acquiring the Drape Contours of Various Fabrics. Fibres Text East Eur 17: $54-59$

8. Filgueiras A, Fangueiro R, Soutinho $F$ (2009) Drape behavior of functional knitted fabrics for sport clothing. Ind J Fibre Textile Res 34: 64-68.

9. Orzada BT, Moore MA, Collier BJ, Chen JY (2009) Effect of laundering on fabric drape, bending and shear. Int J Clothing Sci Technol 21: 44-55.

10. Jer-Yan L, Pin-Ning W, Tien-Wei S (2008) Comparing and Modeling the Dynamic Drape of Four Natural-fiber Fabrics. Textile Res J 78: 911-921.

11. Behera K, Pattanayak AK (2008) Measurement and Modeling of Drape using Digital Image Processing. Ind J Fibre Textile Res 33: 230-238.

12. Sun MN (2008) A New Tester and Method for Measuring Fabric Stiffness and Drape. Textile Res J 78: 761-770.

13. Cui-yu L, Xiao-tao Z (2008) Research and comparison of numerical simulation of draping and buckling about woven fabric and knitted fabric. IEEE 1094-1097.

14. Sular V, Okur A (2008) Objective Evaluation of Fabric Handle by Simple Measurement Methods. Textile Res J 78: 856-868.

15. Ozcelik G, Supuren G, Gulumser T, Tarakcioglu I (2008) A Study on Subjective and Objective Evaluation of the Handle Properties of Shirt Fabrics. Fibres Text East Eur 16: 56-62.

16. Shyr TW, Wang PN, Cheng KB (2007) A Comparison of the Key Parameter Affecting the Dynamic and Static Drape Coefficients of Natural-Fibre Woven Fabrics by a Newly Devised Dynamic Drape Automatic Measuring System. Fibres Text East Eur 15: 81-86.

17. Lojen DZ, Jevsnik S (2007) Some Aspects of Fabric Drape. Fibres Text Eas Eur 15: 39-45.

18. Jung-Whan P, Ae-Gyeong O (2006) Bending Rigidity of Yarns. Textile Res J 76: $478-485$

19. Mizutani C, Amano T, Sakaguchi Y (2005) A New Apparatus for the Study of Fabric Drape. Textile Res J 75: 81-87.

20. Kenkare N, May-Plumlee T (2005) Evaluation of drape characteristics in fabrics. Int J Clothing Sci Technol 17: 109-123.

21. Wang F, Xu G, Xu B (2005) Predicting the Shearing Rigidity of Woven Fabrics Textile Res J 75: 30-34.

22. Sharma KR, Behera BK (2005) Effect of sewing and fusing of interlining on drape behavior of suiting fabrics. Int J Clothing Sci Technol 17: 75-90.

23. Sagar TV, Potluri P (2004) Computation of Bending Behavior of Woven Structures Using Optimization Techniques. Textile Res J 74: 879-886.

24. Sang-Song $L$ (2004) Using drape form to establish discriminant models of fabric characteristics. Ind J Fibre Textile Res 29: 143-148. 